Volume 8. No. 9, September 2020

International Journal of Emerging Trends in Engineering Research

Available Online at http://www.warse.org/IJETER/static/pdf/file/ijeter131892020.pdf

https://doi.org/10.30534/ijeter/2020/131892020

\title{
The Method for Determination of Bone Marrow Cells in Photographic Images
}

\author{
Hennadii Khudov ${ }^{1}$, Igor Ruban ${ }^{2}$, Viktor Lysytsya ${ }^{3}$, \\ Petro Kuzyk ${ }^{4}$, Olesya Symkanych ${ }^{5}$, Rostyslav Khudov ${ }^{6}$, \\ ${ }^{, 1}$ Department of Radar Troops Tactic, Ivan Kozhedub Kharkiv National Air Force University, Kharkiv, Ukraine, \\ 2345kh_hg@ukr.net \\ ${ }^{2}$ Electronic Computer Department, Kharkiv National University of Radio Electronics, Kharkiv, Ukraine, \\ ruban_i@ukr.net \\ ${ }^{3}$ Department of Higher Mathematics and Information Science, V. N. Karazin Kharkiv National University, \\ Kharkiv, Ukraine, lysytsya @karazin.ua \\ ${ }^{4}$ Department of Pathological Anatomy № 2, Bogomolets National Medical University, Kyiv, Ukraine, \\ p.kuzyk@nmu.ua \\ ${ }^{5}$ Department of Pharmaceutical Disciplines, Uzhhorod National University, Uzhhorod, Ukraine, \\ olesjasi123@gmail.com \\ ${ }^{6}$ Department of Theoretical and Applied Informatics, V. N. Karazin Kharkiv National University, Kharkiv, \\ Ukraine, rhudov@gmail.com
}

\begin{abstract}
The automated segmentation of cells in microscopic images is an open research problem that has important implications for studies of the developmental and cancer processes. Known methods for the selection of contours and their main disadvantages are analyzed. A method for isolating the contours of bone marrow cells is proposed. The method includes two stages. The first stage is the selection of contours by the Canny edge detection algorithm. The second stage is the selection of geometric primitives using the Hough transform. The color image of the bone marrow cells was processed. The results of the method at each intermediate stage are given. The assessment of the quality of the selection of the bone marrow cells carried out by visual means.
\end{abstract}

Key words: image, medicine, cytological drug, method for determination, bone marrow cell, photographic images, Canny method, Hough transform.

\section{INTRODUCTION}

Currently, one of the current areas of development of computer technology in medicine is the processing of digital images [1]-[8]. Objects of interest in digital medical images are various organs, tissues, individual parts of the human skeleton, etc., which are obtained using special methods of their visualization: magnetic resonance imaging [2], [9], positron emission tomography [2], [10], ultrasound analysis [2], [11], world and electron microscopy [2]-[4].

Among the many images that allow us to study the human body, especially stand out images of cytological drugs [3]-[4]. Currently, the analysis of images of cytological drugs is carried out mainly manually, which significantly slows down the process, and poor image quality and the presence of a large number of cells in the image increases the probability of error, which leads to incorrect calculations [3]-[4], [12]-[13].

The using of automatic methods of image analysis of cytological drugs will significantly improve the quality of analysis, speed it up. Thus, the automation of object recognition methods on photographic images of cytological preparations is currently relevant. A variety of images of cytological drugs are images of bone marrow cells on a photographic image of low contrast [3]-[4], [12]-[13]. The task of automatically detecting and selecting objects on photographic image of bone marrow cells is very important for medicine and research of human oncological diseases, etc [2], [12]-[13].

The paper is devoted to the processing of such images.

\subsection{Problem analysis}

The peculiarities of cytological drugs are that, on the one hand, they are objects of the micrometer, which allow for more in-depth studies of the human body, study the dynamics of its functioning and diagnose possible diseases in the early stages of their development [13]. On the other hand, photographic images of cytological preparations are special images that differ in the visualization of micrometer objects, which necessitates the use of different processing methods to obtain information about objects, processes and phenomena under study [3]-[4], [13].

In the general case, the processing of photographic images of cytological drugs aims to identify certain parts of the image (cells, nuclei, nucleoli) for further study of their changes (change in shape, cell plane) or calculation of certain 
Hennadii Khudov et al., International Journal of Emerging Trends in Engineering Research, 8(9), September 2020, 5719 - 5725

quantitative characteristics (number of cells, number of cell nuclei, cell planes) [2]. To solve such problems can be used as known methods of determining the contours, and known methods of segmentation [2], [14]-[27].

The most famous edge detectors are: the Roberts operator, Sobel operator, the Prewitt operator, the Kirsch operator, the Robinson operator [1], [17], [22], [24], the Canny algorithm [15], [28]-[29] and the LoG algorithm [22]. When analyzing the results obtained, the following patterns were revealed: Roberts, Sobel and Prewitt operators give very different results. Marr-Hildreth [22], LoG and Canny [15], [28]-[29] almost equally found the contours of the object, Kirsch and Robinson give the same result. But observing the obtained results we can conclude that the Canny algorithm copes much better than others.

In [12] authors present an approach to detect lung cancer in scanned images. The steps involved in it is proposed using methods of image preprocessing where median filter is used followed by segmentation here mathematical morphological operations are used. Geometrical features like area, perimeter, and eccentricity are calculated to tumor detected part. At last SVM classifier is used to classify whether it is cancerous (Malignant) or normal (Benign) [12].

In [30]-[31] it is proposed to use images of cytological preparations using wavelet transform. The visual quality of the image after conversion does not allow to identify all the cells. Further improvement of image quality requires additional pre-processing, which increases processing time and affects the final image processing quality [30]-[31].

One of the most effective methods for finding analytically defined geometric primitives are the methods group which based of Hough transform [18], [23], [32]. These methods can be modified to work with real data on images. When you need to find one or another geometric primitive, which is given an analytical equation. At the same time on the image there is a significant amount of edges or special points[18], [23], [32].

The classic Hough transform was first developed to select straight lines in a binary image rather than circles. It is based on the using of the parameter space, in which the search for lines is performed [18], [23], [32].

The purpose of the article is to develop a method for determining bone marrow cells in a low-contrast photographic image using the Hough transform

\section{MAin MATERial}

Elements of medicine images, such as cells are quite contrasting and contain many circles. Thus, if in each channel of the color space of the color image representation (for example, Red-Green-Blue (RGB)), we select the contours with a edge detector, then using the Hough transformation, we can distinguish geometric primitives. If the geometrical primitive of an object is in all three channels of the RGB at the same time, then this is a sign of the artificial occurrence of the object. If the geometrical primitive of an object is only one channel of color space, then this is the natural object. If the geometrical primitive of an object is only two channels of color space, then the classification is difficult.

Thus, the presented method includes two stages. The first stage is the selection of contours using any edge detection algorithm. The second stage is the selection of geometric primitives using the Hough transform.

The general scheme of the method for selecting the contours of bone marrow cells images is induced in Figure 1.

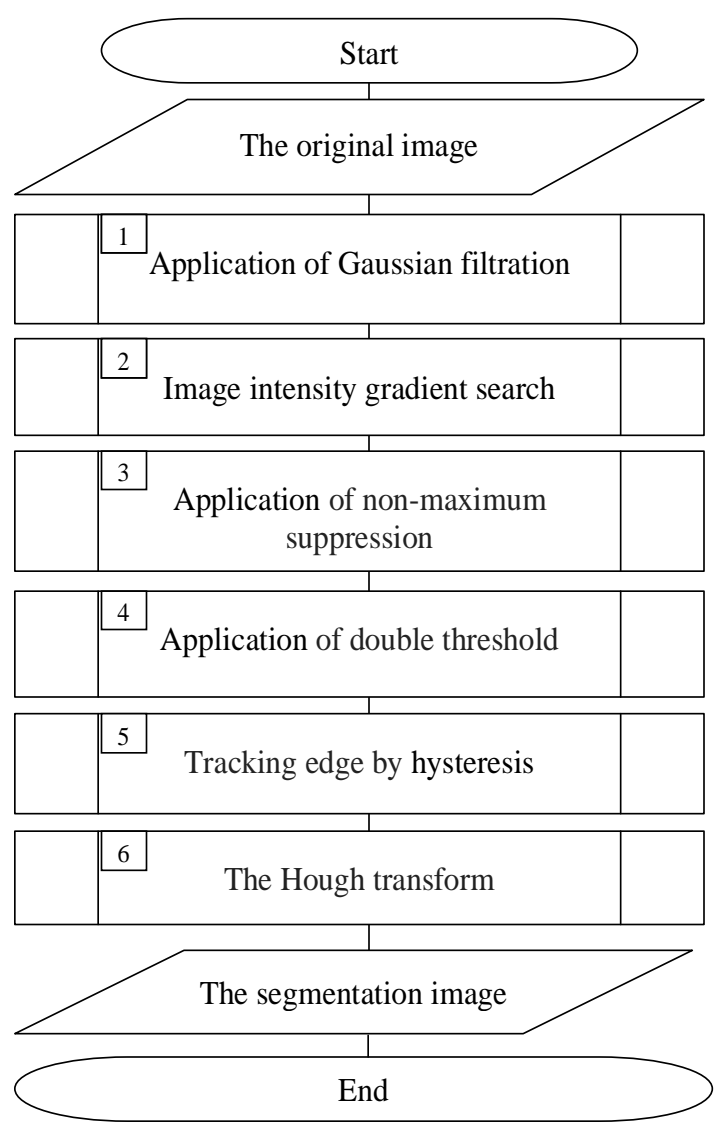

Figure 1: The general scheme of the method for selecting the contours of bone narrow cells images

Blocks from 1 to 4 (Figure 1) can be conditionally attributed to the first stage of the proposed the method for selecting the contours of bone narrow on optoelectronic images. At this stage, the selection of contours is performed using any edge detection algorithm.

Among today's best-known edge detection methods, Canny's edge detection algorithm is one of the best. The Canny edge detection algorithm satisfies three basic criteria:

- good detection (increase in the signal/noise ratio); 
Hennadii Khudov et al., International Journal of Emerging Trends in Engineering Research, 8(9), September 2020, 5719 - 5725

- good localization (correct positioning of the boundary);

- the only response to one border.

Also, this algorithm is easy to implement. So as the edge detection operator we will use the Canny edge detection algorithm

The Canny edge detection algorithm consists of the next different steps:

I. Application of Gaussian filtration (block 1 on Fig. 1). The goal of Gaussian filtration (1) is to smooth the image in order to remove the noise.

$$
f(x, y)=\frac{1}{2 \pi \sigma} \mathrm{e}\left|-\frac{x^{2}+y^{2}}{2 \sigma^{2}}\right|,(1)
$$

where $(x, y)$ - pixel coordinates on the image;

$\mathrm{f}(\mathrm{x}, \mathrm{y})$ - image brightness;

$\sigma-$ blur parameter.

The value of the blur parameter should be chosen so as to provide greater noise suppression. A larger value of the parameter is used to highlight large boundaries, less - to highlight fine details.

II. Image intensity gradient search (block 2 on Figure 1).

To determine the gradient in the image after the Gauss filter (1), we will use the Sobel operator. The basis of the Sobel transform is the assumption that the brightness discontinuity function at the edges becomes much larger.

We can conclude that to find the edges, it is enough to differentiate the brightness function $\mathrm{f}(\mathrm{x}, \mathrm{y})$ (expressions (2), (3)):

$$
\begin{aligned}
& \frac{\partial f(x, y)}{\partial x}=\Delta x=\frac{f(x+d x, y)-f(x, y)}{d x}, \\
& \frac{\partial f(x, y)}{\partial y}=\Delta y=\frac{f(x, y+d y)-f(x, y)}{d y} .
\end{aligned}
$$

In discrete images $\mathrm{dx}$ and $\mathrm{dy}$, you can measure the number of pixels between two points using expressions (4), (5):

$$
\begin{aligned}
& \Delta x=f(i+1, j)-f(i, j), \\
& \Delta y=f(i, j+1)-f(i, j) .
\end{aligned}
$$

The expression for determining the magnitude of the gradient $\mathrm{G}$ can be written as follows (expression (6)):

$$
\mathrm{G}=\sqrt{(\Delta \mathrm{x})^{2}+(\Delta \mathrm{y})^{2}},
$$

and direction $\theta$ (expression (7):

$$
\theta=\arctan \left(\frac{\Delta \mathrm{y}}{\Delta \mathrm{x}}\right)
$$

In expressions (6), (7), the gradient is estimated using kernels $(2 \times 2)$ :

$$
\begin{aligned}
& \Delta \mathrm{x}=\left(\begin{array}{cc}
-1 & 1 \\
0 & 0
\end{array}\right), \\
& \Delta \mathrm{y}=\left(\begin{array}{cc}
-1 & 0 \\
1 & 0
\end{array}\right) .
\end{aligned}
$$

The main disadvantage of using kernels (8) and (9) is a large number of errors due to the presence of noise. In addition, the use of even-order kernels makes it impossible to carry out an assessment based on a pixel that is located in the center of the kernel. Therefore, we will use the Sobel operator with kernels (10), (11):

$$
\begin{aligned}
\mathrm{K}_{\mathrm{G}_{\mathrm{x}}} & =\left(\begin{array}{ccc}
-1 & 0 & 1 \\
-2 & 0 & 2 \\
-1 & 0 & 1
\end{array}\right),(10) \\
\mathrm{K}_{\mathrm{G}_{\mathrm{y}}} & =\left(\begin{array}{ccc}
1 & 2 & 1 \\
0 & 0 & 0 \\
-1 & -2 & -1
\end{array}\right) \cdot(11)
\end{aligned}
$$

From the analysis of expressions (10), (11) (compared to (8), (9)), we can see the use of the coefficient 2 for the middle elements.

The value and direction of the magnitude of the gradient $\mathrm{G}$ take the form (12), (13), respectively:

$$
\begin{gathered}
\mathrm{G}=\sqrt{\mathrm{G}_{\mathrm{x}}^{2}+\mathrm{G}_{\mathrm{y}}^{2}}, \\
\theta=\arctan \left(\frac{\left|\mathrm{G}_{\mathrm{x}}\right|}{\left|\mathrm{G}_{\mathrm{y}}\right|}\right) .
\end{gathered}
$$

After using the Sobel operator, the intensity of each pixel of the original image is equal to the gradient of the brightness vector.

III. Application of non-maximum suppression (block 3 on Figure 1). 
The goal of this stage is to turn blurred edges into "clear" ones. This is achieved by maintaining local maxima and removing the rest. For each pixel, the following actions are performed:

- the direction of the gradient is rounded to the nearest multiple of $45^{0}$;

- if at the current point a local maximum is reached in the direction of the gradient, then it is part of the edge;

- otherwise the point is deleted.

IV. Application of double threshold (block 4 on Figure 1). The goal of double threshold is to determine potential edges.

Each pixel that exceeds the upper threshold is marked as "strong", each pixel that falls between two thresholds is "weak" (the brightness of such points takes a fixed average value and will be refined in the next step). Pixels that are smaller than the lower threshold are deleted.

Using a double threshold allows you to reduce the influence of noise (due to the upper threshold) and not to lose the "tails" (due to the lower threshold).

\section{Tracking edge by hysteresis (block 5 on Figure 1).}

The task is to select groups of pixels that received an intermediate value at the previous stage and assign them to the edge (if they are connected to one of the set edges) or suppress them (otherwise).

This method can avoid artificial interference and realize the threshold self-determination. The advantages of the Canny algorithm are maintained, but it is found that there are still some false edges and edge discontinuities after processing some images, so further improvement is needed.

In the second stage, we use the Hough to image transformation after selecting the edges (block 6 on Figure 1).

The Hough transformation is intended only for the search for lines and circles. This restriction fully satisfies the task of selecting the contours of bone marrow cells images.

The advantages of the Hough transform compared to other approaches to detecting graphics primitives:

- full coverage of possible states and the position of the object (due to a complete search in the standard algorithm).

- the modifiability of the algorithm, which allows to reduce the time of complete enumeration without losing significant information.
The classic Hough transform algorithm was designed to find a line in an image, but later the algorithm was expanded and now it can be used to detect both other parameterizable objects (for example, ellipses, circles, parabolas), and non-parameterizable objects of arbitrary shape.

This method is designed to search for objects belonging to such figures using a voting procedure. The voting procedure applies to the parameter space, from of which objects of a certain class of figures are obtained by the local maximum in the so-called accumulator space when calculating the Hough transformation.

In the simplest case, the Hough transform is a linear transform to detect circles. The equation of a circle with center at a point with coordinates $\left(\mathrm{x}_{0}, \mathrm{y}_{0}\right)$ and radius $\mathrm{R}$ can be represented as (14):

$$
\left(\mathrm{x}-\mathrm{x}_{0}\right)^{2}+\left(\mathrm{y}-\mathrm{y}_{0}\right)^{2}=\mathrm{R}^{2},
$$

and can be calculated for any pair of points in the image (x, y).

When converting Hough the main idea is to take into account the characteristics of the line not as points of the image. Based on this fact, the circle $\left(\mathrm{x}-\mathrm{x}_{0}\right)^{2}+\left(\mathrm{y}-\mathrm{y}_{0}\right)^{2}=\mathrm{R}^{2}$ can be represented as a point with coordinates $(\mathrm{x}, \mathrm{y})$ in the parameter space.

There is the original image (Figure 2 [33]). This image was taken from Carl Zeiss microscope.

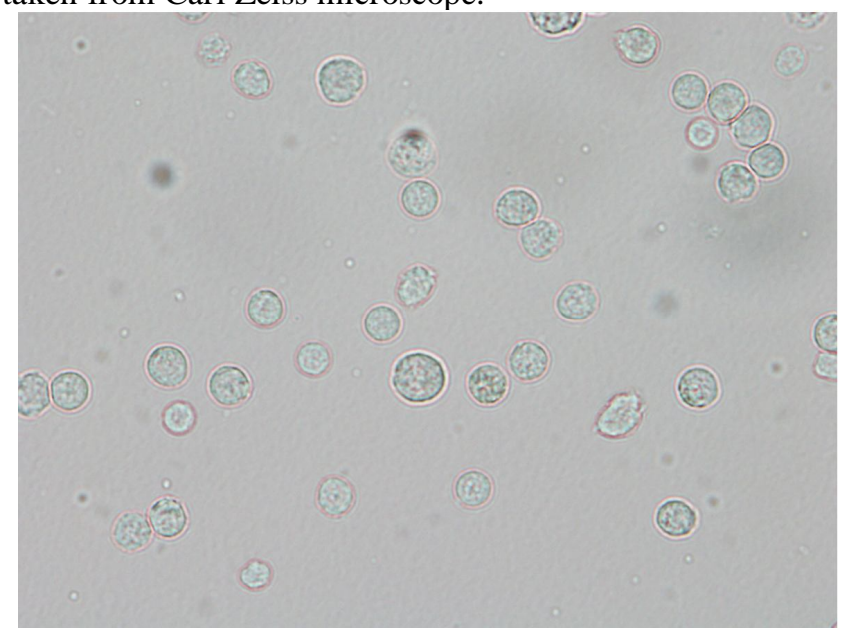

Figure 2: The original image [33]

The result of applying multiplying the brightness of three pixel channels with the same coordinates is shown in Figure 3.

The result of applying to the high contrast image (Figure 3) of the Canny edge detection algorithm is shown in Figure 4.

The Figure 5 shows the result of applying the Hough transform to the image (Figure 4). 
The Figure 5 shows the result of the imposition of Figure 4 on the original image (Figure 2) in order to identify elements of bone narrow cells

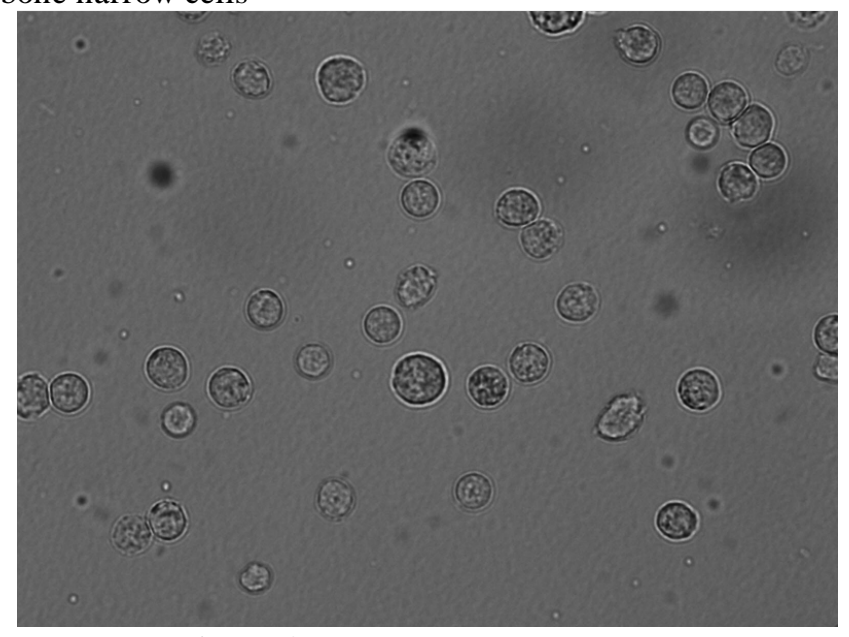

Figure 3: The high contrast images

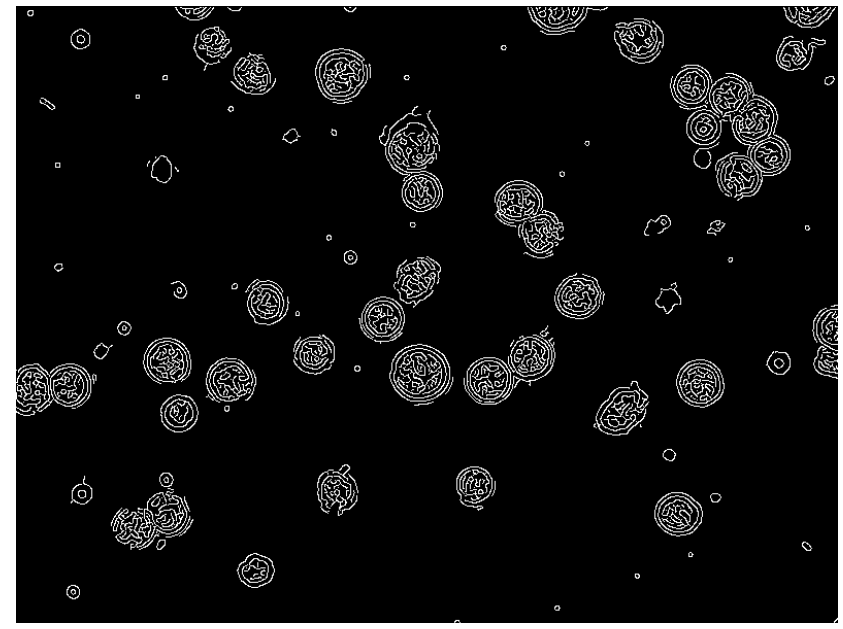

Figure 4: The result of applying to the original image (Figure 2) of the Canny edge detection algorithm

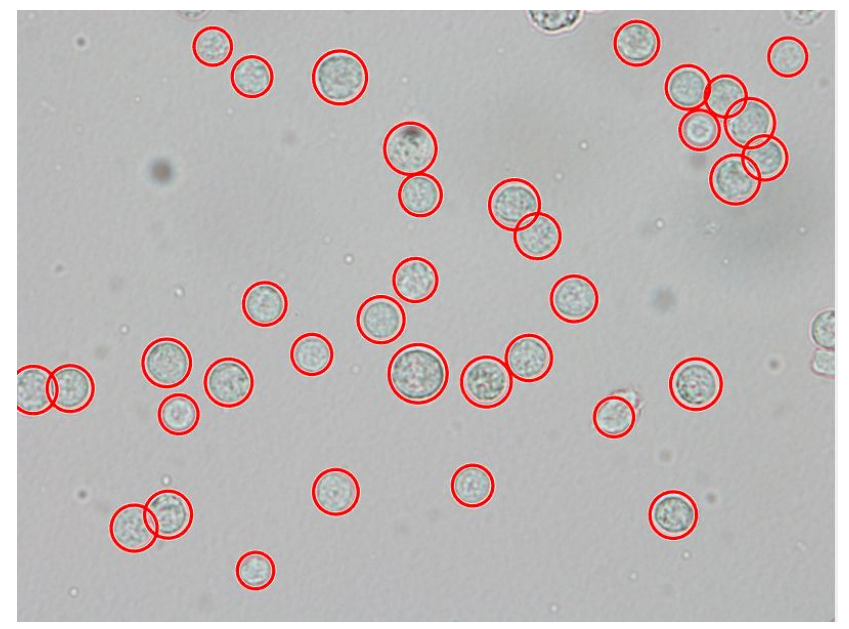

Figure 5: The result of applying the Hough transform to the image (Figure 4)

The Figure 5 shows selected elements of bone narrow cells.

\section{CONCLUSION}

Thus, it is proposed the two-stage method as a method for selecting the contours of bone marrow cells on images of Carl Zeiss microscope. The first stage is the selection of contours by the Canny edge detection algorithm. The second stage is the selection of geometric primitives using the Hough transform.

The assessment of the quality of the selection of the contours of bone narrow cells on the image carried out by visual means. To improve the performance of this method, it is promising to use a multi-scale image processing method.

\section{REFERENCES}

1. R. Gonzalez, and R. Woods, Digital Image Processing. 4th Edition. Prentice Hall, Upper Saddle Rever, 2017. $1192 \mathrm{p}$.

2. A. El-Baz, X. Jiang, and S. Jasjit (Eds.) Biomedical image segmentation: advances and trends.. CRC Press, 2016. $546 \mathrm{p}$.

3. A. I. Bozhkov, S. L. Ohiienko, A. Yu. Bondar, E. M. Klimova, and E. G. Ivanov Liver-induced fibrosis in young and old animals is accompanied by agedependent changes in bone marrow cells. Advances in Gerontology. 2019. Vol. 32 (1-2). P. 45-54.

4. S. L. Ohiienko, A. Yu. Bondar, E. G. Ivanov, and I. A. Ionov Bonemarrow cells obtained from old animals differ from the young animals cells in their ability to divide and in response to the presence of liver fibrosis in primary culture. Advances in Aging Research. 2019. Vol. 8. P. 14-27.

5. P. V. Kuzyk, M. A. Savchyna, S. G. Gychka Rare case of nodular lymphoid hyperplasia of left lung in the patient with previous pulmonary tuberculosis Experimental Oncology, Vol. 40. № 4, 2018, P. 332-335. DOI:

https://doi.org/10.31768/2312-8852.2018.40(4):332-335

6. N. Bakhmat, B. Maksymchuk, O. Voloshyna, V. Kuzmenko, T. Matviichuk, A. Kovalchuk, and I. Maksymchuk Designing cloud-oriented university environment in teacher training of future physical education teachers. Journal of Physical Education and Sport, Vol. 19, № 4, 2019, P. 1323-1332. http://efsupit.ro/images/stories/august2019/Art\% 20192.pdf

7. L. Behas, B. Maksymchuk, I. Babii, S. Tsymbal-Slatvinska, N. Golub, V. Golub, and I. Maksymchuk The influence of tempo rhythmic organization of speech during gaming and theatrical activities on correction of stammering in children. Journal of Physical Education and Sport, Vol. 19, № 4, 2019 , P. 1333-1340. http://efsupit.ro/images/stories/august2019/Art\% 20193.pdf 
Hennadii Khudov et al., International Journal of Emerging Trends in Engineering Research, 8(9), September 2020, 5719 - 5725

8. O. Bezliudnyi, O. Kravchenko, B. Maksymchuk, M. Mishchenko and I. Maksymchuk Psycho-correction of burnout syndrome in sports educators (2019). Journal of Physical Education and Sport, Vol. 19, № 3, 2019 Art 230 pp. 1585. http://efsupit.ro/images/stories/septembrie201 9/Art\%20230.pdf

9. S. Schluter, A. Sheppard, K. Brown, and D. Wildenschild Image processing of multiphase images obtained via X-ray microtomography: a review. Water Resources Research. 2014. T. 50. № 4. P. 3615-3639.

10. O. Gaemperli, J. Shalhoub, D. Owen, F. Lamare, S. Johansson, N. Fouladi, A. Davies, O. Rimoldi, and $P$. Camici Imaging intraplaque inflammation in carotid atherosclerosis with 11C-PK11195 positron emission tomography/computed tomography. European heart journal. 2012. T. 33. № 15. P. 1902-1910.

11. S. Sikdar, H. Rangwala, E. Eastlake, I. Hunt, A. Nelson, J. Devanathan, A. Shin, J. Pancrazio, and S. Sikdar Novel method for predicting dexterous individual finger movements by imaging muscle activity using a wearable ultrasonic system. IEEE Transactions on Neural Systems and Rehabilitation Engineering. 2014. T. 22. № 1. P. 69-76.

12. D. Nagajyothi, R. Addagudi, T. Gunda, S. Logitla, and G. Arun Detection of Lung Cancer using SVM Classifier, International Journal of Emerging Trends in Engineering Research, № 8(5), 2020, pp. 2177-2180. DOI: https://doi.org/10.30534/ijeter/2020/113852020.

13. S. L. Ohiienko, A. Yu. Bondar, E. G. Ivannov, and A. I. Bozhkov Liver fibrosis has a different effect on the "lifespan" of lymphocytes and neutrophils in the in vitrosystem isolated from the bone marrow of young and old rats MOJ Gerontol \& Geriatrics. 2019. Vol. 4. № 1. P. 36-40.

14. H. Khudov, S. Glukhov, V. Podlipaiev, V. Pavlii, I. Khizhnyak, and I. Yuzova The Multiscale Image Processing Method from On-board Earth Remote Sensing Systems Based on the Artificial Bee Colony Algorithm International Journal of Advanced Trends in Computer Science and Engineering, Vol. 9. № 3, 2020, P. 2557-2562.

DOI: https://doi.org/10.30534/ijatcse/2020/11932020.

15. H. Khudov, R. Khudov, I. Khizhnyak, V. Loza, T. Kravets, S. Kibitkin Estimation of the Kullback-Leibler Divergence for Canny Edge Detector of Optoelectronic Images Segmentation, International Journal of Emerging Trends in Engineering Research, Vol. 8. № 7, 2020, pp. 3927-3934. DOI: https://doi.org/10.30534/ijeter/2020/162872020.

16. I. Ruban, H. Khudov, O. Makoveychuk, I. Khizhnyak, V. Khudov, and V. Lishchenko The model and the method for forming a mosaic sustainable marker of augmented reality. 2020 IEEE 15 th Inter. Conf. on Advanced Trends in Radioelectronics,
Telecommunications and Engineering (TCSET), February 2020.

https://doi.org/10.1109/TCSET49122.2020.235463.

17. I. Ruban, and H. Khudov, Advances in Spatio-Temporal Segmentation of Visual Data, Chapter 2. Swarm Method of Image Segmentation. Series Studies in Computational Intelligence (SCI), Vol. 876. - Publisher Springer, Cham, $2020 . \quad-\quad$ P. 53-99. DOI https://doi.org/10.1007/978-3-030-35480-0.

18. I. Ruban, H. Khudov, O. Makoveichuk, I. Khizhnyak, N. Lukova-Chuiko, G. Pevtsov, Y. Sheviakov, I. Yuzova, Y. Drob, and O. Tytarenko, Method for determining elements of urban infrastructure objects based on the results from air monitoring, Eastern-European Journal of Enterprise Technologies, № 4/9 (100), 2019, pp. 52-61.

DOI:

https://doi.org/10.15587/1729-4061.2019.174576.

19. H. Khudov, I. Ruban, O. Makoveichuk, H. Pevtsov, V. Khudov, I. Khizhnyak, S. Fryz, V. Podlipaiev, Y. Polonskyi, and R. Khudov. Development of methods for determining the contours of objects for a complex structured color image based on the ant colony optimization algorithm, Eureka: Physics and Engineering, № 1, 2020, pp. 34-47. DOI: https://doi.org/10.21303/2461-4262.2020.001108.

20. I. Ruban, H. Khudov, O. Makoveichuk, M. Chomik, V. Khudov, I. Khizhnyak, V. Podlipaiev, Y. Sheviakov, O. Baranik, and A. Irkha. Construction of methods for determining the contours of objects on tonal aerospace images based on the ant algorithms, Eastern-European Journal of Enterprise Technologies, № 5/9 (101), 2019, pp. 25-34.

DOI: https://doi.org/10.15587/1729-4061.2019.177817.

21. I. Ruban, V. Khudov, H. Khudov, and I. Khizhnyak An Improved Method for Segmentation of a Multiscale Sequence of Optoelectronic Images, in Intern. Scient.-Pract. Conf. Problems of Infocommunications. Science and Technology (PIC S\&T), 2017, pp. 137-140. DOI: https://doi.org/10.1109/INFOCOMMST.2017.8246 367

22. K. Smelyakov, O. Ponomarenko, A. Chupryna, D. Tovchyrechko, and I. Ruban Local Feature Detectors Performance Analysis on Digital Image 2019 IEEE International Scientific-Practical Conference Problems of Infocommunications, Science and Technology (PIC $S \& T), 8-11$ Oct. 2019, Kyiv, Ukraine. P. 644-648.

23.I. Ruban, O. Makoveichuk, V. Khudov, I. Khizhnyak, H. Khudov, I. Yuzova, and Y. Drob. The Method for Selecting the Urban Infrastructure Objects Contours, in Intern. Scient.-Pract. Conf. Problems of Infocommunications. Science and Technology (PIC S\&T), 2019, pp. 689-693. DOI: https://doi.org/10.1109/infocommst.2018.8632045.

24. H. Khudov, O. Makoveychuk, I. Khizhnyak, I. Yuzova , A. Irkha, and V. Khudov. The Mosaic Sustainable Marker Model for Augmented Reality Systems, International Journal of Advanced Trends in Computer 
Hennadii Khudov et al., International Journal of Emerging Trends in Engineering Research, 8(9), September 2020, 5719 - 5725

Science and Engineering, Vol. 9. № 1, 2020, pp. 637-642.

DOI: https://doi.org/10.30534/ijatcse/2020/89912020.

25. I. Ruban, H. Khudov, V. Khudov, I. Khizhnyak, and O. Makoveichuk. Segmentation of the images obtained from onboard optoelectronic surveillance systems by the evolutionary method, Eastern-European Journal of Enterprise Technologies, № 5/9 (89), 2017, pp. 49-57. DOI: https://doi.org/10.15587/1729-4061.2017.109904.

26. I. Ruban, V. Khudov, O. Makoveichuk, H. Khudov, and I. Khizhnyak. A Swarm Method for Segmentation of Images Obtained from On-Board Optoelectronic Surveillance Systems, in Intern. Scient.-Pract. Conf. Problems of Infocommunications. Science and Technology (PICS\&T), 2018, pp. 613-618. DOI: https://doi.org/10.1109/infocommst.2018.8632045.

27. I. Ruban, H. Khudov, O. Makoveichuk, I. Khizhnyak, V. Khudov, V. Podlipaiev, V. Shumeiko, O. Atrasevych, A. Nikitin, and R. Khudov. Segmentation of opticalelectronic images from on-board systems of remote sensing of the Earth by the artificial bee colony method, Eastern-European Journal of Enterprise Technologies, № 2/9 (98), 2019, pp. 37-45. DOI: https://doi.org/10.15587/1729-4061.2019.161860.

28. J. F. Canny Computational Approach to Edge Detection IEEE Transactions on Pattern Analysis and Machine Intelligence. 1986. № 8. - P. 679-698.

29. A. Kabade, and V. Sangam Canny edge detection algorithm International Journal of Advanced Research in Electronics and Communication Engineering (IJARECE). 2016. Vol. 5. Issue 5. P. 1292-1295.

30. V. V. Lyashenko, A. M. Babker, and O. A. Kobylin Using the methodology of wavelet analysis for processing images of cytology preparations National Journal of Medical Research. 2016. T. 6. № 1. P. 98-102.

31. V. V. Lyashenko, A. M. Babker, and O. A. Kobylin The methodology of wavelet analysis as a tool for cytology preparations image processing Cukurova Medical Journal. 2016. T. 41. № 3. C. 453-463.

32. A. Manzanera, T. Nguyen, and X. Xu Line and circle detection using dense one-to-one Hough transforms on greyscale images EURASIP Journal on Image and Video Processing, Springer. - 2016. № 34. P. 1773-2000.

33. Roche Digital Diagnostics, URL: https://diagnostics.roche.com/global/en/products/product -category/roche-digital-diagnostics0.html (accessed 17 August 2020). 